\title{
Recycling of plastic waste: Screening for brominated flame retardants (BFRs)
}

\author{
Pivnenko, Kostyantyn; Granby, Kit; Eriksson, Eva; Astrup, Thomas Fruergaard
}

Published in:

Waste Management

Link to article, DOI:

10.1016/j.wasman.2017.08.038

Publication date:

2017

Document Version

Peer reviewed version

Link back to DTU Orbit

Citation (APA):

Pivnenko, K., Granby, K., Eriksson, E., \& Astrup, T. F. (2017). Recycling of plastic waste: Screening for brominated flame retardants (BFRs). Waste Management, 69, 101-109.

https://doi.org/10.1016/j.wasman.2017.08.038

\section{General rights}

Copyright and moral rights for the publications made accessible in the public portal are retained by the authors and/or other copyright owners and it is a condition of accessing publications that users recognise and abide by the legal requirements associated with these rights.

- Users may download and print one copy of any publication from the public portal for the purpose of private study or research.

- You may not further distribute the material or use it for any profit-making activity or commercial gain

- You may freely distribute the URL identifying the publication in the public portal

If you believe that this document breaches copyright please contact us providing details, and we will remove access to the work immediately and investigate your claim 
Manuscript accepted for publication in Waste Management journal:

http://www.sciencedirect.com/science/article/pii/S0956053X17306165

\section{RECYCLING OF PLASTIC WASTE: SCREENING FOR BROMINATED FLAME RETARDANTS (BFRs)}

K. PIVNENKO ${ }^{a}$, K. GRANBY ${ }^{b}$, E. ERIKSSON ${ }^{a}$, T.F. ASTRUP ${ }^{a}$

${ }^{a}$ Department of Environmental Engineering, Technical University of Denmark, DK-2800 Kgs. Lyngby, Denmark

${ }^{b}$ National Food Institute, Technical University of Denmark, DK-2860 Søborg, Denmark

*) Corresponding author: Kostyantyn Pivnenko

Department of Environmental Engineering, Technical University of Denmark, DK-2800 Kgs.

Lyngby, Denmark

kosp@env.dtu.dk

Telephone: +45 4525 1602, fax: +45 45932850

"NOTE: this is the author's version of a work that was accepted for publication in Waste Management journal. Changes resulting from the publishing process, such as peer review, editing, corrections, structural formatting, and other quality control mechanisms may not be reflected in this document. Minor changes may have been made to this manuscript since it was accepted for publication. A definitive version is published in Waste Management, https://doi.org/10.1016/j.wasman.2017.08.038" 


\begin{abstract}
Flame retardants are chemicals vital for reducing risks of fire and preventing human casualties and property losses. Due to the abundance, low cost and high performance of bromine, brominated flame retardants (BFRs) have had a significant share of the market for years. Physical stability on the other hand, has resulted in dispersion and accumulation of selected BFRs in the environment and receiving biota. A wide range of plastic products may contain BFRs. This affects the quality of waste plastics as secondary resource: material recycling may potentially reintroduce the BFRs into new plastic product cycles and lead to increased exposure levels, e.g. through use of plastic packaging materials. To provide quantitative and qualitative data on presence of BFRs in plastics, we analysed bromophenols (tetrabromobisphenol A (TBBPA), dibromophenols (2,4- and 2,6-DBP) and 2,4,6-tribromophenol (2,4,6-TBP)), hexabromocyclododecane stereoisomers $(\alpha-, \beta$-, and $\gamma$ HBCD), as well as selected polybrominated diphenyl ethers (PBDEs) in samples of household waste plastics, virgin and recycled plastics. A considerable number of samples contained BFRs, with highest concentrations associated with acrylonitrile butadiene styrene (ABS, up to 26,000,000 ng TBBPA/g) and polystyrene (PS, up to 330,000 ng $\sum \mathrm{HBCD} / \mathrm{g}$ ). Abundancy in low concentrations of some BFRs in plastic samples suggested either unintended addition in plastic products or degradation of higher molecular weight BFRs. The presence of currently restricted flame retardants (PBDEs and HBCD) identified in the plastic samples illustrates that circular material flows may be contaminated for extended periods. The screening clearly showed a need for improved documentation and monitoring of the presence of BFRs in plastic waste routed to recycling.
\end{abstract}

Keywords: Tetrabromobisphenol A (TBBPA); hexabromocyclododecane (HBCD); bromophenol; POPs; additives. 


\section{Abbreviations}

ABS; Acrylonitrile butadiene styrene

BFR; Brominated flame retardant

DBP; Dibromophenol

ePS; Expanded polystyrene

EU; European Union

HBCD; Hexabromocyclododecane

HDPE; High-density polyethylene

HIPS; High-impact polystyrene

LDPE; Low-density polyethylene

LDPE(L); Linear low-density polyethylene

LOD; Limit of detection

NSP; Non-specific plastic

PBDE; Polybrominated diphenyl ether

PET; Polyethylene terephthalate

PET(G); Polyethylene terephthalate glycol-modified

PO; Polyolefin

POP; Persistent organic pollutant

PP; Polypropylene

PS; Polystyrene

RHW; Residual household waste

RSD; Relative standard deviation

SSHW; Source-segregated household waste

TBBPA; Tetrabromobisphenol A (CAS 79-94-7)

WEEE; Waste electric and electronic equipment

a-HBCD; Alpha hexabromocyclododecane (CAS 134237-50-6)

$\beta$-HBCD; Beta hexabromocyclododecane (CAS 134237-51-7)

$\gamma$-HBCD; Gamma hexabromocyclododecane (CAS 134237-52-8)

2,4-DBP; 2,4-dibromophenol (CAS 615-58-7)

2,6-DBP; 2,6-dibromophenol (CAS 608-33-3)

2,4,6-TBP; 2,4,6-tribromophenol (CAS 118-79-6) 


\section{Introduction}

Flame retardants are chemical substances introduced into flammable materials in order to increase resistance towards fire (WHO, 1997). There are indisputable benefits of flame retardants in relation to life saving and reducing property damages as the result of fires. Flame retardants are partially responsible for reduced fire incidents across the globe (Birnbaum and Staskal, 2004). There is a plethora of different types of flame retardants currently available on the market; these are commonly divided into four main classes: halogenated organic (bromine or chlorine containing), phosphorous-containing, nitrogen-containing, and inorganic (Birnbaum and Staskal, 2004). Among the halogenated organics, bromine-based chemicals have prevailed due to bromine's higher free radical trapping efficiency and lower decomposition temperature (Guerra et al., 2011). Furthermore, brominated flame retardants (BFRs) can be subsequently divided into five main classes: brominated bisphenols, diphenyl ethers, cyclododecanes, phenols, and phthalic acid derivatives; the first three represent the majority of the BFR market (Birnbaum and Staskal, 2004). Driven by more stringent fire safety measures in developing economies and increasing use of plastics in the construction sector, the market for flame retardants is expected to grow (Freedonia, 2013; Grand View Research, 2016; ICL, 2015). Phosphorous-based substances were forecast to be the fastest-growing types (ICL, 2015), surpassing BFRs in market size in 2015 (Freedonia, 2017). While, global market shares for BFRs decreased from approximately $36 \%$ in 2004 (Mack, 2004) to $25 \%$ in 2014 (Zion, 2015), introduction of novel halogenated retardants could support partial gains (ICL, 2015).

The single BFRs with the highest global production volumes are tetrabromobisphenol A (TBBPA; 170,000 tonnes in 2004 (George and Häggblom, 2008)), polybrominated diphenyl ethers (PBDEs; approximately 70,000 tonnes in 2001 (CP/RAC, 2009)) and hexabromocyclododecanes (HBCDs; approximately 23,000 tonnes in 2011 (UNEP, 2011)). However, the demand for PBDEs has been in constant decline worldwide (Harrad et al., 2008) and current PBDEs production 
volumes are expected to be lower. Although HBCD can have a total of 16 isomers, $\alpha-$, $\beta-$, and $\gamma-$ HBCD are the ones commonly used in commercial mixtures, with $\gamma$-HBCD being the most abundant (Heeb et al., 2005). Phenol-based BFRs, such as 2,4-dibromophenol (2,4-DBP), 2,4,6tribromophenol (2,4,6-TBP), pentabromophenol, etc. have been identified as an emerging class of flame retardants (Bergman et al., 2012; Covaci et al., 2011; EFSA, 2012; Wit et al., 2011). Among those, in particular 2,4,6-TBP is used in the highest quantities in the European Union (EU) $(1,000$ $10,000 \mathrm{t} / \mathrm{a}$ ), primarily as an intermediate for production of other flame retardants such as TBBPA (Miljøstyrelsen, 2014). Dibromophenols (DBPs including 2,4 and 2,6-DBP), as well as 2,4,6-TBP may also result from thermal or UV decomposition of TBBPA as well as selected PBDEs (Barontini et al., 2004; Bendig and Vetter, 2013; de Wit, 2002; Eriksson, 1998).

The persistent nature of flame retardants in general and the brominated ones in particular, allows them to be accumulated and detected in humans and the environment in areas far away from the points of production or consumption (Covaci et al., 2006; Law et al., 2006; Meironyté et al., 1999). BFRs exert a variety of toxic effects, which differ depending on the BFR group in focus and dose it appears at (Darnerud, 2003). According to a recent publication from the International Agency for Research on Cancer (IARC), and reflecting on "sufficient evidence of carcinogenicity in experimental animals", TBBPA has been upgraded to group 2A (probably carcinogenic to humans) (Grosse et al., 2016). The concerns related to human health and the environment resulted in a ban (EC, 2003) and restrictions on use of selected BFRs $(<0.1 \%$ for Polybrominated biphenyls and PBDE (EC, 2011)) within the EU. Selected PBDEs and HBCD have also been included in the list of chemicals covered by the Stockholm Convention on Persistent Organic Pollutants (POPs), promoting their elimination in use and imposing a ban on recycling of products containing BFRs. Under the REACH regulation (EC, 2006), in 2015 HBCD has been classified as a substance of very high concern with only authorized production and use. 
Flame retardants in plastics are mostly associated with the construction sector, electric and electronic equipment, textiles, and furniture where BFRs are commonly added to polymers as highimpact polystyrene (HIPS) and polystyrene (PS) foam, polyterephthalate, unsaturated polyesters, epoxy resins, etc. (Alaee et al., 2003; Birnbaum and Staskal, 2004; Koch et al., 2015). BFRs can be incorporated in different ways into the polymers, and thus commonly divided into groups such as: additive, reactive, and polymeric (Mack, 2004). While additive and polymeric BFRs are simply blended into a polymer, reactive BFRs are chemically bonded into polymer matrix. HBCD and TBBPA are common examples of additive and reactive BFRs, respectively. Studies have shown the presence of a variety of BFRs in the polymer fraction of waste electric and electronic equipment (WEEE), raising concerns about the fate of BFRs in potential waste management practices (Schlummer et al., 2007, 2005). Polymers commonly found in WEEE include PS, acrylonitrile butadiene styrene (ABS), polycarbonate blends, HIPS and polypropylene (PP) (Martinho et al., 2012). Selected BFRs have been found in food contact materials and children's toys purchased on the European market (Ionas et al., 2014; Puype et al., 2015; Samsonek and Puype, 2013). Puype et al., (2015) as well as Samsonek and Puype (2013) suggested that presence of BFRs in food contact plastics may be the result of contamination of the polymer products with recycled plastics potentially derived from WEEE. Although BFR levels found in food samples are mostly associated with environmental contamination, potential influence from packaging cannot be excluded (Schecter et al., 2012). Finally, alternative management of waste materials containing BFRs may also create environmental issues e.g., generation of contaminated leachate from landfills (Osako et al., 2004) or formation of toxic chemicals (i.e. dioxins and furans) upon incineration (Weber and Kuch, 2003). The current knowledge of BFRs in waste materials is limited. In order to ensure safe and intelligent recycling and management of the materials, further documention of the presence of BFRs in plastic articles and waste plastics is needed. 
The overall aim of this study was to provide an improved overview of the presence of BFRs in household waste plastics, as well as virgin and recycled plastics collected from industry. This involved quantification of selected BFRs: TBBPA (CAS 79-94-7), dibromophenols (2,4-DBP and 2,6-DBP, CAS 615-58-7 and CAS 608-33-3), 2,4,6-TBP (CAS 118-79-6), $\alpha-, \beta-$, and $\gamma$-HBCD (CAS 134237-50-6, CAS 134237-51-7, and CAS 134237-52-8), as well as screening of selected PBDEs: BDE-47, BDE-85, BDE-99, BDE-100, BDE-153 and BDE-154.

\section{Materials and methods}

\subsection{Sample collection and pre-treatment}

A schematic representation of a generic plastic product lifecycle is provided in Figure 1. The figure also indicates the sources of plastic samples addressed in this study (e.g., virgin plastics). Samples of waste plastics were collected from residual (\#1-13, Table 1) and source-segregated (\#14-20, Table 1) household waste from a Danish municipality in April 2013. The waste stream derived from at least 100 households and represented waste generation and collection over two weeks for each household. Details of the sampling campaign can be found elsewhere (Edjabou et al., 2015). After being sampled, waste plastics were manually sorted into plastic packaging and other plastics, in

total 14 fractions. Sorting and identification of polymer types followed the internationally accepted classification system, which includes marking plastic packaging with a code 1-7 (ASTM D7611). Plastic items not bearing the classification code were combined in a single fraction (non-specific plastics (NSPs)), which could potentially contain any plastics commonly used in households. Metalcoated and uncoated plastic foils were categorized in separate fractions; commonly made of polyethylene, PP or polyvinyl chloride plastic resins. The details of the individual plastic fractions are presented in Table 1. 


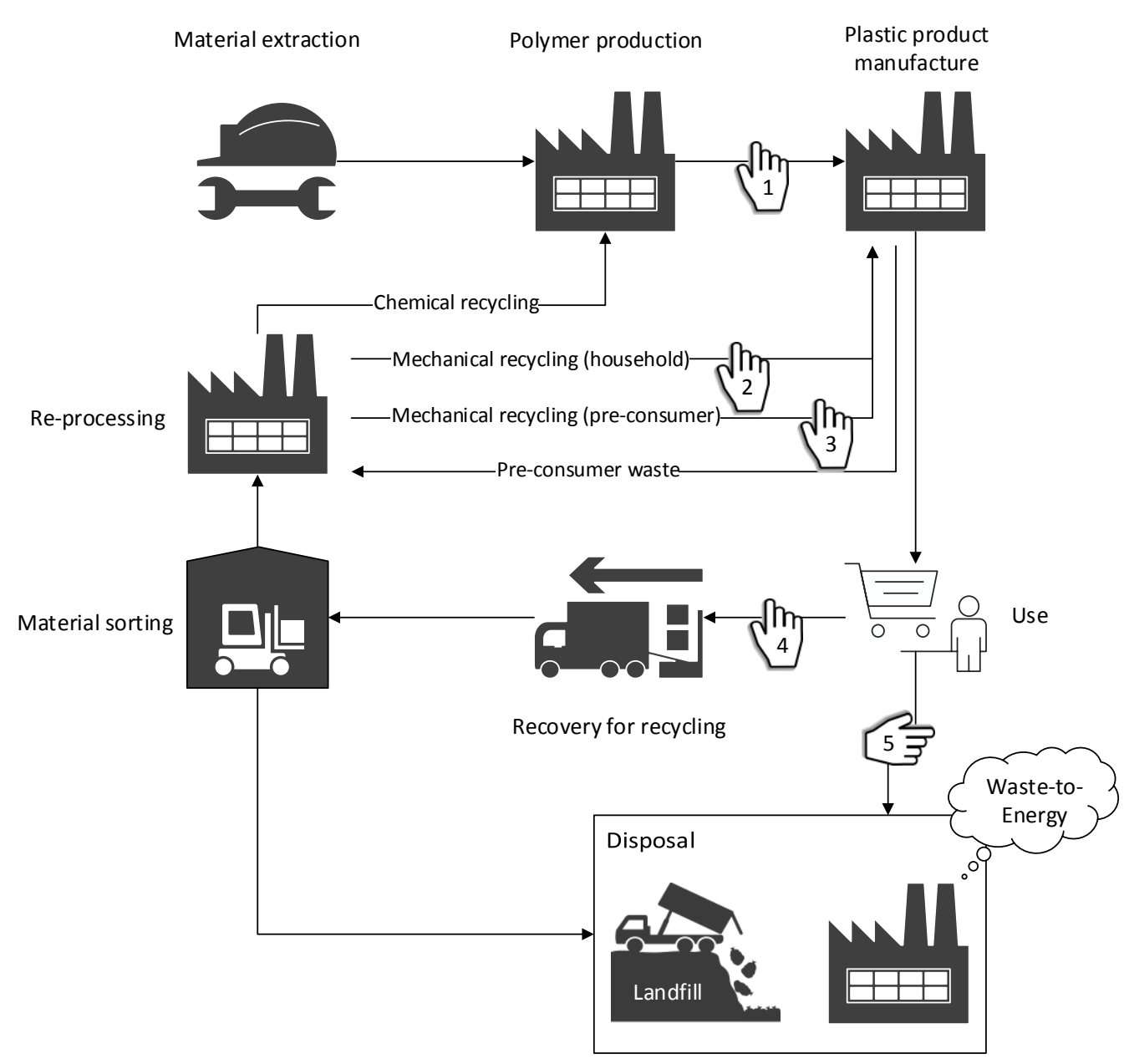

Figure 1. Schematic representation of a generic plastic product lifecycle with points of sampling indicated (1. Virgin plastics; 2. Recycled household plastics; 3. Recycled pre-consumer plastics; 4. Source-segregated household waste plastics; 5. Residual waste plastics from mixed waste).

After being sorted into the individual fractions, the waste plastics were coarsely shredded (ARP SC2000, Brovst, Denmark), and then finely shredded (SM2000, Retsch, Germany) after being treated with liquid nitrogen to increase the material brittleness. The particle size of the finely shredded plastics was $<1 \mathrm{~mm}$.

Samples of processed plastics (virgin and recycled) were collected from a variety of plastics producers and recyclers in China, Denmark, Germany, and the Netherlands. Obtained samples were 
not anticipated to represent plastics composition on the global market or in the respective countries, but provide quantitative and qualitative screening of BFRs in samples from a variety of suppliers in different countries. The samples of processed plastics were not pre-treated but were analysed as received in the form of flakes, granules or pellets. Details of the collected samples are provided in Table 2.

\subsection{Sample extraction}

Sample extraction and analysis were performed in accordance with a modified accredited method FC412.1 (DANAK, 2015). A subsample of $1 \mathrm{~g}$ was taken from each of the samples. The influence of particle size on release of the substances of interest was not assessed in the present work. The plastic samples were added to $20 \mathrm{ml}$ of extraction solvent composed of $n$-hexane and isopropanol $(1: 1 \mathrm{v} / \mathrm{v})$. The extraction was performed in a microwave sample preparation system (Multiwave 3000, Anton Paar, Graz, Austria) involving heating to $100^{\circ} \mathrm{C}$ for 60 minutes, followed by a gradual cooling. After this, sample and extraction solvent were centrifuged at $2500 \mathrm{rpm}$ for $5 \mathrm{~min}$. The liquid phase was decanted, a mixture of deuterated ${ }^{13} \mathrm{C}_{12}-\alpha$-HBCD and ${ }^{13} \mathrm{C}_{12}$-TBBPA (Wellington laboratories, Guelph, Canada) was added as an internal standard, and the volume reduced to $1.5 \mathrm{ml}$ in a water-bath rotary evaporator (Rotavapor R-205, Büchi, Switzerland) at $40^{\circ} \mathrm{C}$. The final extracts were filtered using Mini uniprep $0.2 \mu \mathrm{m}$ polypropylene filter vials (Whatman, UK) before being analysed on a high-performance liquid chromatographer (HPLC) coupled to a tandem mass spectrometer (MS/MS) or a gas chromatographer (GC) coupled to a quadrupole time-of-flight mass spectrometer (QTOF/MS). 


\subsection{Chemical analyses}

\section{Bromophenols and $H B C D$}

The quantitative analyses were performed on a HPLC (Agilent Technologies, Paolo Alto, USA) coupled to a MS/MS (Micromass Quatro, Waters, Hertfordshire, UK). The separation took place on a reverse phase chromatographic column (Kinetex, Phenomenex, Allerød, Danmark), using a gradient of methanol and $0.01 \%$ acetic acid at $0.2 \mathrm{ml} / \mathrm{min}$. The source and desolvation temperatures were $120{ }^{\circ} \mathrm{C}$ and $380{ }^{\circ} \mathrm{C}$, respectively. The collision energy was $35 \mathrm{eV}$ and the Argon collision gas pressure was kept at 2.3e-3 mbar. The quantification was made using the external calibration method $\left(r^{2}>0.99\right)$ with compensation for recovery of the internal standard. Certified calibration standards of TBBPA, $\alpha-, \beta-$, and $\gamma$-HBCD were purchased from Wellington laboratories (Ontario, Canada), while 2,4-DBP, 2,6-DBP, and 2,4,6-TBP were from Sigma-Aldrich (Brøndby, Denmark). The limit of detection (LOD) was calculated from analysis of four blank samples, as the average plus three times the standard deviation (see detailed LODs in Table 1 and 2). Method recoveries, i.e. ratios of measured analyte concentrations to spiked concentrations of the analyte in a sample of plastics (low-density polyethylene, LDPE), were calculated to be $113 \%$ and $117 \%$ for 2,4,6-TBP and $\alpha-H B C D$, respectively. Concentrations reported in this work were not compensated for the method recovery. Extraction and analysis of replicates for four waste plastic samples resulted in following relative standard deviations: $31 \%$ (DBPs), $10 \%(2,4,6-\mathrm{TBP}), 10 \%$ (TBBPA), $9 \%(\alpha-$ HBCD), $8 \%(\beta-H B C D)$ and $19 \%(\gamma-\mathrm{HBCD})$.

\section{Polybrominated diphenyl ethers}

Detection was performed on a GC coupled to a QTOF/MS with a PAL injector (GC-sampler 80) (Agilent Technologies, Paolo Alto, USA). The carrier gas was helium with a flow rate of 1.2 
$\mathrm{ml} / \mathrm{min}$ and the programmed temperature vaporizing (PTV) injection with volume of $1 \mu \mathrm{l}$. The PTV temperature programme was $50{ }^{\circ} \mathrm{C}$ for $0.8 \mathrm{~min}$, increasing $480{ }^{\circ} \mathrm{C} / \mathrm{min}$ to $290{ }^{\circ} \mathrm{C}$ hold $2 \mathrm{~min}$, and $720{ }^{\circ} \mathrm{C} / \mathrm{min}$ to $330{ }^{\circ} \mathrm{C}$ hold for $10 \mathrm{~min}$. The initial GC temperature was $70{ }^{\circ} \mathrm{C}$ for $3 \mathrm{~min}$, increasing $20{ }^{\circ} \mathrm{C} / \mathrm{min}$ to $310^{\circ} \mathrm{C}$, hold for $10 \mathrm{~min}$. The gas separation was performed on two DB5 MS columns $15 \mathrm{~m}$ (Agilent J\&W GC columns). The quadrupole was set to allow masses between 50 and $500 \mathrm{Da}$ to pass and reach the time-of-flight mass analyser. A technical PBDE congener mix was purchased from Cambridge Isotopes Laboratories Inc. (Andover, MA, USA). The PBDE mix was applied for identification of congeners as follows (order according to the retention time): BDE-47 (27 \% w/w), BDE-100 (17 \% w/w), BDE-99 (37\% w/w), BDE-85 (4 \% w/w), BDE-154 (6 \% w/w) and BDE$153(8 \% \mathrm{w} / \mathrm{w})$. The GC-QTOF/MS chromatogram illustrating the selected PBDEs and their molecular structures is provided in Figure 2.

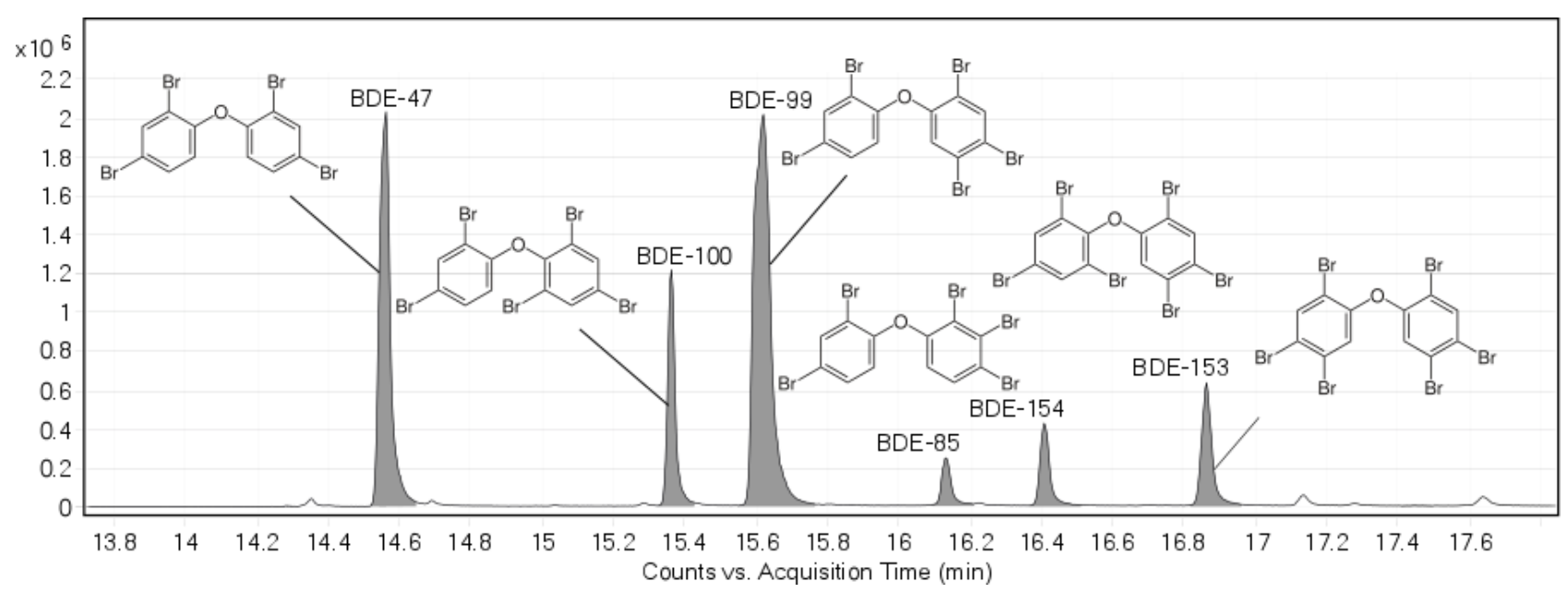

Figure 2. GC-QTOF/MS chromatogram of the PBDE technical mix used in the present work.

\section{Results and Discussion}

The details of the individual plastic samples, the measured concentrations of TBBPA, HBCD, and bromophenols, as well as the screening results for PBDE are presented in Table 1 and 2. Most of the 
substances were identified with higher frequency in waste plastics (Table 1) when compared to the processed plastics (Table 2). The BFRs identified most often in waste plastics (approx. $50 \%$ of the samples) were DBPs and $\alpha$-HBCD. The remaining bromophenols were found in $40 \%$ of the samples, while $35 \%$ of waste plastics contained $\beta$ - and $\gamma$-HBCD. In contrast, the most common BFRs identified in processed plastics were TBBPA and BDE-99 (37 \%), followed by BDE-47 (29 $\%), \alpha-\operatorname{HBCD}(26 \%)$, DBPs and 2,4,6-TBP (20\%), and the remaining BFRs in less than $10 \%$ of the cases.

\section{$<$ Table 1>}

\section{$\langle$ Table 2>}

\subsection{Bromophenols}

By far the highest concentrations of bromopehnols were found in a sample of recycled ABS (Table 2). TBBPA was measured to be $26,000,000 \mathrm{ng} / \mathrm{g}(2.6 \% \mathrm{w} / \mathrm{w})$, followed by $2,4,6-\mathrm{TBP}(340,000$ $\mathrm{ng} / \mathrm{g})$ and DBPs $(8,000 \mathrm{ng} / \mathrm{g})$. The use of TBBPA and 2,4,6-TBP as the first and second most prevalent flame retardants in $\mathrm{ABS}$ has been documented previously (Norwegian Environment Agency, 2016; Weil and Levchik, 2009). ABS is one of the most common polymers found in WEEE and contains TBBPA as flame retardant (Martinho et al., 2012; Schlummer et al., 2007). Concentrations of TBBPA in ABS have been reported as high as 10-20\% (w/w) in certain applications (Covaci et al., 2009). Among the bromophenols analysed in waste plastics, TBBPA was present in higher concentrations ranging from 20 to $4400 \mathrm{ng} / \mathrm{g}$. The highest concentrations were associated with samples of PS (4400 ng/g), PP (3000 ng/g) and NSP (2200 ng/g) from residual household waste. These values are somewhat lower than $8,100 \mathrm{ng} / \mathrm{g}$ of TBBPA found in plastics used for TV housings (Choi et al., 2009). On the other hand, TBBPA was not identified in any of 
the virgin plastic samples analysed; only measurable concentrations of DBPs and $\alpha$-HBCD were found in two PS samples.

DBPs and 2,4,6-TBP were predominantly identified in the samples of waste plastics rather than in the processed plastics (Table 1 and 2). In contrast to the relatively "well-established" BFRs such as TBBPA, DBPs and 2,4,6-TBP are among the emerging or novel BFRs; at least in relation to situations when DBPs and 2,4,6-TBP are intentionally applied and added in polymers, which might not always be the case. Di- and tribromphenols can potentially result from TBBPA thermal (Barontini et al., 2004) and biological degradation (An et al., 2011), from PBDE physical (Bendig and Vetter, 2013) or biological degradation (Stapleton et al., 2008), or even be natuarally produced (Gribble, 2000). TBBPA has also been shown to photodegrade under natural light, with accelerated degradation rates under UV exposure (Liu et al., 2016). TBBPA decomposes at temperatures between $200-300{ }^{\circ} \mathrm{C}$ (JRC, 2006), while melting points of the common thermoplastics can reach $245^{\circ} \mathrm{C}$. Substance purity of TBBPA has been reported to be close to $99 \%$ with water being the main impurity (JRC, 2006). Nevertheless, TBBPA of lower purity may also contain brominated phenol compounds (including di- and tribromophenols) as impurity (McKinnie and Sharp, 1993). In our study, sample \#33 (Table 2) contained $1.3 \%(2,4,6-\mathrm{TBP})$ and $0.03 \%$ (DBPs) relative to the mass of TBBPA present. Finally, neither TBBPA degradation, nor presence of impurities could explain concentrations of DBPs as the only bromophenol measured in waste plastic samples \#2, 3, 8, 15 (Table 1) and processed plastic samples \#7, 8, 27, 31 (Table 2).

The presence of brominated phenols in plastics raises concern due to their low molecular weights and potential for release from the polymer matrix. For example, presence of organohalogens (including 2,4-DBP, 2,6-DBP and 2,4,6-TBP in concentrations of $1.3,0.7$ and $33.9 \mathrm{ng} / \mathrm{g}$, respectively) in Australian high-density polyethylene (HDPE) milk containers resulted in public 
opposition and consumer complaints (Robertson, 2012). This was partially the result of bromophenols migration from the packaging into the milk in concentrations exceeding respective odor and taste thresholds. Additionally, 2,4-DBP and 2,4,6-TBP are among the top three chemicals by mass estimated to be released from plastics in Sweden each year (Chemitecs, 2010).

\subsection{Hexabromocyclododecane (HBCD)}

All samples of waste PS contained HBCD, with a single sample of expanded PS packaging containing the highest concentrations of all the HBCD isomers, reaching 330,000 ng/g $(0.033 \%$ $\mathrm{w} / \mathrm{w}$ ) of total HBCD ( $\mathrm{HBCD}$ ). PS depolymerises into highly flammable chemicals (styrene monomer, styrene dimers, benzene, lower-alkylbenzenes, etc.) when exposed to elevated temperatures (Švec, 1990), which could increase the potential risks of fire and justify addition of flame retardants in some PS applications. Addition of HBCD in PS-based polymers (expanded PS, extruded PS, etc.) can be as high as $3 \%$ in the final polymer (Koch et al., 2015; NEA, 2013). While such high concentrations are mainly expected in construction applications, expanded PS used as packaging (ice box, disposable trays, etc.) has been shown to contain up to $960,000 \mathrm{ng} / \mathrm{g} \sum \mathrm{HBCD}$ (Rani et al., 2013). Similarly, among the plastic products collected from a local market in China, $\mathrm{Hu}$ et al. (2012) found significant concentrations of $\sum \operatorname{HBCD}(108,000$ and 333,000 ng/g) only in PS. In addition to our PS samples, HBCD was also found in the NSP samples (630 and $3200 \mathrm{ng} / \mathrm{g}$ for packaging and non-packging residual household waste, respectively) and polyethylene terephthalate, PET (1300 ng/g) waste plastics. While HBCD in NSP can be related to the presence of un-identifiable PS present in the samples, the source of HBCD in non-packaging PET waste is unclear. While PET with polymer identifications is almost exclusively used in packaging (plastic bottles and other food and non-food packaging), still a small share of PET is used in other applications (PlasticsEurope, 2015a). 
Among the HBCD isomers, Heeb et al. (2005) have shown that the $\gamma$-HBCD is the prevailing isomer in technical HBCD mixtures. This is evident from the sample of waste expanded PS (\#5, Table 1) which contained $16 \%, 7 \%$ and $77 \%$ of $\alpha-, \beta-$, and $\gamma$-HBCD, respectively. However, this isomer distribution is different from most of the samples analysed in the study, as $\alpha$-HBCD was the prevailing isomer in the majority of cases for both waste and processed plastics (Table 1 and 2). It has been shown that exposing HBCD containing materials to temperatures $>100{ }^{\circ} \mathrm{C}$ induces transformation of $\gamma-\mathrm{HBCD}$ into $\alpha-\mathrm{HBCD}$, altering the diastereometric ratio of the HBCD mixture (Heeb et al., 2008). Heeb et al. (2008) have also shown a six-fold increase in the isomerization rate when exposure temperature increased from 120 to $140{ }^{\circ} \mathrm{C}$. These temperature is comparable or lower than the melting points of common thermoplastics, which range between 135 and $245{ }^{\circ} \mathrm{C}$ (Goodship, 2007). This explains the dominance of $\alpha$-HBCD in most of the recycled plastic samples (Table 2). Likewise, Kajiwara et al. (2009) predominantly found $\alpha$-HBCD in textile samples, indicating heat isomerization of $\gamma$-HBCD or higher retention of the alpha isomer in the fabric. Although studies providing a toxicological profile of individual HBCD isomers are extremely rare (Law et al., 2005; Schecter et al., 2012), the more lipophilic nature of $\alpha$-HBCD and its up to 17 times higher biological half-life (Schecter et al., 2012) may result in longer transportation distances and higher bioaccumulation potential in comparison with the other isomers (Davis et al., 2006). Similarly, Schecter et al. (2012) more frequently (and in higher concentrations) identified the $\alpha$ isomer when analysing HBCD in food samples.

\subsection{Polybrominated diphenyl ethers (PBDEs)}

The screening for PBDEs in plastics showed their presence mostly in samples of processed plastics (both virgin and recycled), while only two samples of household waste plastics contained traces of PBDEs. The presence in plastics of the targeted PBDEs, and particularly in virgin plastics, is rather 
surprising as penta-PBDE has been classified as a POP and listed under the Stockholm Convention from 2009 (UN, 2009). Most of the PBDE congeners were identified in a sample of processed PS (\#7, Table 2) and polyolefins, POs (\#34, Table 2). The most common PBDE identified in processed plastics was BDE-99. The abundancy of PBDE congeners $(\%, w / w)$ in the penta-PBDE technical flame-retardant mixtures (La Guardia et al., 2006) followed the same order of frequency in detection as presented in Table 2 (BDE-99>BDE-47>BDE-100>BDE-153>BDE-154). Such clear correspondence between the analytical results and the congener profile of a technical mixture of PBDE indicates an insignificant potential for transformation. Taking into consideration the current restrictions in PBDE use and a general decline in production, their presence in samples of recycled plastics could be attributed to contamination through recycling, i.e. when older plastic products containing PBDE are recycled into new plastics. Similarly, Ionas et al. (2014) and Kajiwara et al. (2011) illustrated relatively high detection rates and low concentration levels for PBDEs in plastic children's toys and selected consumer products, potentially attributing their findings to contamination through plastic recycling (Ionas et al., 2014; Kajiwara et al., 2011).

\subsection{Brominated flame retardants and plastic recycling}

Plastic recycling processes are not designed to remove chemical contaminants embedded in the plastic waste materials. Hence, BFRs as well as other chemical contaminants contained in obsolete plastic products can remain in the materials after re-processing and thereby be re-introduced into the plastic material loop. This means that chemicals included in one type of plastic products (e.g., part of electric and electronic equipment) may subsequently be introduced into plastics used for other applications, potentially resulting in additional health risks and jeopardising consumer acceptance of recycled products. Recycling of plastic waste has previously been suggested as a potential source of contaminants in recycled plastic materials and products (Ionas et al., 2014; Pivnenko et al., 
2016a). Flame retardants have been shown to be present in plastic products in concentrations not sufficiently high to provide effective flame retardancy. Among other this could indicate unintended spreading of flame retardants through recycling. Based on our results, this could be the case for TBBPA which was quantified only in samples of recycled plastics, within the group of processed plastic samples (Table 2). TBBPA containing recycled plastics has been shown to maintain the thermal stability even after four recycling passes, indicating no significant removal or degradation of TBBPA during plastic recycling process (Imai et al., 2003). Similarly, six out of seven samples of recycled PP contained traces of selected BFRs, while both virgin PP samples contained no detectable levels of bromophenols and HBCD. Again, this indicates a more pronounce presence in recycled PP. In addition, combined use of BFRs in plastics is rare (Puype et al., 2015), hence the presence of multiple BFRs in individual samples (e.g., \#34, Table 2) may be the direct result of polymer mixes from different sources, and consequently of contamination during the recycling stage. The "legacy" of chemical contamination should also be of concern, as the presence of restricted or phased-out chemicals in waste materials can last for decades (Pivnenko et al., 2016b), depending primarily on the service life-span of plastic products (e.g., construction materials vs. short-lived packaging materials). Similarly, the PBDE traces found predominantly in the recycled plastic samples could indicate legacy contamination from phased-out BFRs. HBCD and PBDEcontaining plastic waste would not be allowed for recycling, since HBCD "production and use" is prohibited under the current EU legislation and penta-PBDE is characterized as a POP. ABS and PS are of particular concern, as these plastic types are commonly used in electric and electronic equipment and may contain relatively high concentrations of TBBPA and HBCD as demonstrated in this study. Accounting for almost $10 \%(\mathrm{w} / \mathrm{w})$ of the European plastics demand (PlasticsEurope, 2015b), ABS and PS recycling is of potential interest, but the presence of BFRs should be closely monitored to insure high quality of the recycled polymers. Our results further suggested that 
transformation of $\gamma$-HBCD to $\alpha-\mathrm{HBCD}$ may occur, either as a direct result of plastic production or during recycling processes, which usually involve exposure of the plastics to elevated temperatures. While plastics recycling can offer potential economic and environmental benefits and should be promoted, quality rather than quantity targets for plastics recycling and close monitoring of the quality of waste plastics from different sources is essential to achieve sustainable plastic material cycles.

\section{Conclusions}

A wide range of plastic samples from households as well as production and recycling industries were evaluated for contents of brominated flame retartants, BFRs. A considerable share of the plastics samples contained BFRs, predominantly in the household waste and recycled plastics. The highest concentrations were found in ABS (up to 26,000,000 ng TBBPA/g) and PS (up to 330,000 ng $\left.\sum \mathrm{HBCD} / \mathrm{g}\right)$. Relatively low concentrations and abundancy of di- and tri-bromophenols were observed for the analysed samples. This might indicate unintentional addition (e.g., as impurity or through plastics recycling), or result from degradation of higher molecular weight BFRs (i.e. TBBPA or even PBDEs). Positive identification of selected PBDEs and HBCD in the samples emphasized potential "legacy contamination" when banned or restricted chemicals persist in material recycling, unless routed towards appropriate final sinks or destruction. The presence of multiple BFRs in individual samples may be the direct result of polymer mixing and contaminantion during plastic recycling. Among the HBCD isomers, $\alpha-\mathrm{HBCD}$ was the dominant isomer indicating potential isomeric transformation of $\mathrm{HBCD}$ during plastic production or reprocessing and recycling. The results from this study clearly indicate that use of recycled plastic in sensitive applications (e.g., food-contact materials, toys and childcare articles) requires close monitoring of the plastic waste quality prior to recycling. This involves both the waste source and 
the potential presence of contaminants (including BFRs), particularly with respect to polymers commonly used in electric and electronic equipment (e.g., ABS and PS).

\section{Acknowledgements}

The authors would like to thank Vera Lykkerask Berg and Lisbeth Krüger Jensen (National Food Institute, DTU) for their help with the analyses and acknowledge the financial support of the Danish Research Council through the 3R Research School and the IRMAR project (grant no. 11-116775).

\section{References}

Alaee, M., Arias, P., Sjödin, A., Bergman, A., 2003. An overview of commercially used brominated flame retardants, their applications, their use patterns in different countries/regions and possible modes of release. Environ. Int. 29, 683-9. doi:10.1016/S0160-4120(03)00121-1

An, T., Zu, L., Li, G., Wan, S., Mai, B., Wong, P.K., 2011. One-step process for debromination and aerobic mineralization of tetrabromobisphenol-A by a novel Ochrobactrum $\mathrm{sp}$. T isolated from an e-waste recycling site. Bioresour. Technol. 102, 9148-9154. doi:10.1016/j.biortech.2011.06.080

Barontini, F., Marsanich, K., Petarca, L., Cozzani, V., 2004. The Thermal Degradation Process of Tetrabromobisphenol A. Ind. Eng. Chem. Res. 43, 1952-1961. doi:10.1021/ie034017c

Bendig, P., Vetter, W., 2013. UV-induced formation of bromophenols from polybrominated diphenyl ethers. Environ. Sci. Technol. 47, 3665-3670. doi:10.1021/es304785f

Bergman, Å., Rydén, A., Law, R.J., de Boer, J., Covaci, A., Alaee, M., Birnbaum, L., Petreas, M., Rose, M., Sakai, S., Van den Eede, N., van der Veen, I., 2012. A novel abbreviation standard for organobromine, organochlorine and organophosphorus flame retardants and some characteristics of the chemicals. Environ. Int. 49, 57-82. doi:10.1016/j.envint.2012.08.003

Birnbaum, L.S., Staskal, D.F., 2004. Brominated flame retardants: cause for concern? Environ. Health Perspect. 112, 9-17.

Chemitecs, 2010. National inventory of emissions of additives from plastic materials. Swedish Environmental Protection Agency. Göteborg, Sweden.

Choi, K.-I., Lee, S.-H., Osako, M., 2009. Leaching of brominated flame retardants from TV housing plastics in the presence of dissolved humic matter. Chemosphere 74, 460-6.

doi:10.1016/j.chemosphere.2008.08.030

Covaci, A., Gerecke, A.C., Law, R.J., Voorspoels, S., Kohler, M., Heeb, N. V., Leslie, H., Allchin, C.R., de Boer, J., 2006. Hexabromocyclododecanes (HBCDs) in the Environment and Humans: A Review. Environ. Sci. Technol. 40, 3679-3688. doi:10.1021/es0602492 
Covaci, A., Harrad, S., Abdallah, M.A.E., Ali, N., Law, R.J., Herzke, D., de Wit, C.A., 2011. Novel brominated flame retardants: A review of their analysis, environmental fate and behaviour. Environ. Int. 37, 532-556. doi:10.1016/j.envint.2010.11.007

Covaci, A., Voorspoels, S., Abdallah, M.A.-E., Geens, T., Harrad, S., Law, R.J., 2009. Analytical and environmental aspects of the flame retardant tetrabromobisphenol-A and its derivatives. J. Chromatogr. A 1216, 346-63. doi:10.1016/j.chroma.2008.08.035

CP/RAC, 2009. Report on Brominated Flame-retardants in Mediterranean countries. Regional Activity Centre for Cleaner Production. Barcelona, Spain.

DANAK, 2015. FC412.1 Bestemmelse af Tetrabrombisphenol A (TBBPA), $\alpha-, \beta-, \gamma-$ Hexabromocyclododecan (HBCD) og Bromophenoler i fødevarer ved LC-MS/MS, The Danish Accreditation Fund (DANAK).

Darnerud, P.O., 2003. Toxic effects of brominated flame retardants in man and in wildlife. Environ. Int. 29, 841-53. doi:10.1016/S0160-4120(03)00107-7

Davis, J.W., Gonsior, S.J., Markham, D.A., Friederich, U., Hunziker, R.W., Ariano, J.M., 2006. Biodegradation and product identification of [14C]hexabromocyclododecane in wastewater sludge and freshwater aquatic sediment. Environ. Sci. Technol. 40, 5395-401.

de Wit, C.A., 2002. An overview of brominated flame retardants in the environment. Chemosphere 46, 583-624. doi:10.1016/S0045-6535(01)00225-9

EC, 2003. Directive 2003/11/EC of the European parliament and of the council of February 62003 amending for the 24th time Council Directive 76/669/EEC relating to restrictions on the marketing and use of certain dangerous substances and preparations. Off. J. Eur. Union 16, 4546.

EC, 2006. Regulation No 1907/2006 of the European Parliament and the Council of 18 December 2006 concerning the Registration, Evaluation, Authorisation and Restriction of Chemicals (REACH), establishing a European Chemicals Agency. Off J Eur Union L396: 1-849.

EC, 2011. Directive 2011/65/EU of the European Parliament and of the Council of 8 June 2011 on the restriction of the use of certain hazardous substances in electrical and electronic equipment (RoHS). Off. J. Eur. Union 54, 88-110. doi:10.1017/CBO9781107415324.004

Edjabou, M.E., Jensen, M.B., Götze, R., Pivnenko, K., Petersen, C., Scheutz, C., Astrup, T.F., 2015. Municipal solid waste composition: Sampling methodology, statistical analyses, and case study evaluation. Waste Manag. 36, 12-23. doi:10.1016/j.wasman.2014.11.009

EFSA, 2012. Report of ESCO WG on non-plastic Food Contact Materials, European Food Safety Authority (EFSA), Parma, Italy 1-63.

Eriksson, P., 1998. Developmental neurotoxicity of brominated flame-retardants, polybrominated diphenyl ethers and tetrabrom-bis-phenol A. Organohalogen Compd. 35, 375-378.

Freedonia, 2013. World demand for flame retardants forecast to grow 5.4\% per year till 2016. Addit. Polym. 2013, 10-11. doi:10.1016/S0306-3747(13)70099-X

Freedonia, 2017. Global Flame Retardants Market By Country, Product and Market, 6th Edition. Freedonia. ID: 4895342.

George, K.W., Häggblom, M.M., 2008. Microbial O-Methylation of the Flame Retardant Tetrabromobisphenol-A. Environ. Sci. Technol. 42, 5555-5561. doi:10.1021/es800038q 
Goodship, V., 2007. Introduction to Plastics Recycling, Second Edi. ed. Smithers Rapra Press.

Grand View Research, 2016. Flame Retardant Market Analysis By Product (Halogenated (Brominated, Antimony Trioxide), Non Halogenated (Aluminum Hydroxide, Magnesium Dihydroxide, Phosphorous)), By Application, By End-Use And Segment Forecasts, 2014 2025. Grand View Research. ID: 3972817.

Gribble, G.W., 2000. The natural production of organobromine compounds. Environ. Sci. Pollut. Res. Int. 7, 37-47. doi:10.1065/espr199910.002

Grosse, Y., Loomis, D., Guyton, K.Z., El Ghissassi, F., Bouvard, V., Benbrahim-Tallaa, L., Mattock, H., Straif, K., 2016. Carcinogenicity of some industrial chemicals. Lancet. Oncol. 17, 419-420. doi:10.1016/S1470-2045(16)00137-6

Guerra, P., Alaee, M., Eljarrat, E., Barceló, D., 2011. Introduction to Brominated Flame Retardants: Commercially Products, Applications, and Physicochemical Properties, in: Eljarrat, E., Barceló, D. (Eds.), Brominated Flame Retardants, The Handbook of Environmental Chemistry. Springer Berlin Heidelberg, Berlin, Heidelberg, pp. 1-17. doi:10.1007/978-3-642-19269-2

Harrad, S., Ibarra, C., Diamond, M., Melymuk, L., Robson, M., Douwes, J., Roosens, L., Dirtu, A.C., Covaci, A., 2008. Polybrominated diphenyl ethers in domestic indoor dust from Canada, New Zealand, United Kingdom and United States. Environ. Int. 34, 232-8. doi:10.1016/j.envint.2007.08.008

Heeb, N. V., Bernd Schweizer, W., Mattrel, P., Haag, R., Gerecke, A.C., Schmid, P., Zennegg, M., Vonmont, H., 2008. Regio- and stereoselective isomerization of hexabromocyclododecanes (HBCDs): Kinetics and mechanism of $\gamma$ - to $\alpha$-HBCD isomerization. Chemosphere 73, $1201-$ 1210. doi:10.1016/j.chemosphere.2008.07.045

Heeb, N. V, Schweizer, W.B., Kohler, M., Gerecke, A.C., 2005. Structure elucidation of hexabromocyclododecanes--a class of compounds with a complex stereochemistry. Chemosphere 61, 65-73. doi:10.1016/j.chemosphere.2005.03.015

Hu, D., Hu, X., Li, J., Wang, P., Guo, S., 2012. Determinations of hexabromocyclododecane (HBCD) isomers in plastic products from China by LC-MS/MS. J. Liq. Chromatogr. Relat. Technol. 35, 558-572. doi:10.1080/10826076.2011.604111

ICL, 2015. Worldwide flame retardants market to reach 2.8 million tonnes in 2018. Addit. Polym. 2015, 11. doi:10.1016/S0306-3747(15)30046-4

Imai, T., Hamm, S., Rothenbacher, K.P., 2003. Comparison of the Recyclability of Flame-Retarded Plastics. Environ. Sci. Technol. 37, 652-656. doi:10.1021/es025771c

Ionas, A.C., Dirtu, A.C., Anthonissen, T., Neels, H., Covaci, A., 2014. Downsides of the recycling process: harmful organic chemicals in children's toys. Environ. Int. 65, 54-62. doi:10.1016/j.envint.2013.12.019

JRC, 2006. European Union Risk Assessment Report, 2,2',6,6'-tetrabromo-4,4'isopropylidenediphenol (tetrabromobisphenol-A or TBBP-A), Part II - human health. Joint Research Center (JRC), Institute for Health and Consumer Protection, European Chemicals Bureau. Ispra, Italy.

Kajiwara, N., Noma, Y., Takigami, H., 2011. Brominated and organophosphate flame retardants in selected consumer products on the Japanese market in 2008. J. Hazard. Mater. 192, 1250-9. doi:10.1016/j.jhazmat.2011.06.043 
Kajiwara, N., Sueoka, M., Ohiwa, T., Takigami, H., 2009. Determination of flame-retardant hexabromocyclododecane diastereomers in textiles. Chemosphere 74, 1485-9. doi:10.1016/j.chemosphere.2008.11.046

Koch, C., Schmidt-Kötters, T., Rupp, R., Sures, B., 2015. Review of hexabromocyclododecane (HBCD) with a focus on legislation and recent publications concerning toxicokinetics and dynamics. Environ. Pollut. 199, 26-34. doi:10.1016/j.envpol.2015.01.011

La Guardia, M.J., Hale, R.C., Harvey, E., 2006. Detailed polybrominated diphenyl ether (PBDE) congener composition of the widely used penta-, octa-, and deca-PBDE technical flameretardant mixtures. Environ. Sci. Technol. 40, 6247-6254. doi:10.1021/es060630m

Law, R.J., Allchin, C.R., de Boer, J., Covaci, A., Herzke, D., Lepom, P., Morris, S., Tronczynski, J., de Wit, C.A., 2006. Levels and trends of brominated flame retardants in the European environment. Chemosphere 64, 187-208. doi:10.1016/j.chemosphere.2005.12.007

Law, R.J., Kohler, M., Heeb, N. V., Gerecke, A.C., Schmid, P., Voorspoels, S., Covaci, A., Becher, G., JanAk, K., Thomsen, C., 2005. Hexabromocyclododecane Challenges Scientists and Regulators. Environ. Sci. Technol. 39, 281A-287A. doi:10.1021/es053302f

Liu, C., Niu, X., Song, X., 2016. A simulation research on the natural degradation process of tetrabromobisphenol A in soil under the atmospheric different environments. Environ. Sci. Pollut. Res. 23, 16406-16416. doi:10.1007/s11356-016-6767-1

Mack, A.G., 2004. Flame Retardants , Halogenated. Kirk-Othmer Encycl. Chem. Technol. 11, 454483. doi:10.1002/0471238961.0801121516052020.a01.pub2

Martinho, G., Pires, A., Saraiva, L., Ribeiro, R., 2012. Composition of plastics from waste electrical and electronic equipment (WEEE) by direct sampling. Waste Manag. 32, 1213-7. doi:10.1016/j.wasman.2012.02.010

McKinnie, B., Sharp, G., 1993. Process for high purity tetrabromobisphenol-A (US5208389 A).

Meironyté, D., Norén, K., Bergman, A., 1999. Analysis of polybrominated diphenyl ethers in Swedish human milk. A time-related trend study, 1972-1997. J. Toxicol. Environ. Health. A $58,329-41$.

Miljøstyrelsen, 2014. Survey of brominated flame retardants, Environmental Project No. 1536. Mijøstyrelsen (Danish EPA). Copenhagen, Denmark.

NEA, 2013. Hazardous substances in plastic materials (TA-3017/2013), Norwegian Environment Agency (NEA). Oslo, Norway.

Norwegian Environment Agency, 2016. Substance evaluation conclusion as required by REACH Article 48 and evaluation report for 2,4,6-tribromophenol. Trondheim, Norway.

Osako, M., Kim, Y.-J., Sakai, S., 2004. Leaching of brominated flame retardants in leachate from landfills in Japan. Chemosphere 57, 1571-9. doi:10.1016/j.chemosphere.2004.08.076

Pivnenko, K., Eriksen, M.K., Martín-Fernández, J.A., Eriksson, E., Astrup, T.F., 2016a. Recycling of plastic waste: Presence of phthalates in plastics from households and industry. Waste Manag. 54, 44-52. doi:10.1016/j.wasman.2016.05.014

Pivnenko, K., Laner, D., Astrup, T.F., 2016b. Material Cycles and Chemicals: Dynamic Material Flow Analysis of Contaminants in Paper Recycling. Environ. Sci. Technol. acs.est.6b01791. doi:10.1021/acs.est.6b01791 
PlasticsEurope, 2015a. Plastics - the facts 2014/2015. An analysis of European plastics production, demand and waste data, Association of Plastics Manufacturers. Brussels, Belgium.

PlasticsEurope, 2015b. Plastics - The Facts 2015. An analysis of European plastics production, demand and waste data. Association of Plastics Manufacturers (PlasticsEurope). Brussels, Belgium.

Puype, F., Samsonek, J., Knoop, J., Egelkraut-Holtus, M., Ortlieb, M., 2015. Evidence of waste electrical and electronic equipment (WEEE) relevant substances in polymeric food-contact articles sold on the European market. Food Addit. Contam. Part A 49, 150119061656008. doi:10.1080/19440049.2015.1009499

Rani, M., Shim, W.J., Han, G.M., Jang, M., Song, Y.K., Hong, S.H., 2013. Hexabromocyclododecane in polystyrene based consumer products: An evidence of unregulated use. Chemosphere 110, 111-119. doi:10.1016/j.chemosphere.2014.02.022

Robertson, G.L., 2012. Food Packaging: Principles and Practice, Third Edition. CRC Press, Florida, USA.

Samsonek, J., Puype, F., 2013. Occurrence of brominated flame retardants in black thermo cups and selected kitchen utensils purchased on the European market. Food Addit. Contam. Part A 30, 1976-1986.

Schecter, A., Szabo, D.T., Miller, J., Gent, T.L., Malik-Bass, N., Petersen, M., Paepke, O., Colacino, J. a., Hynan, L.S., Robert Harris, T., Malla, S., Birnbaum, L.S., 2012.

Hexabromocyclododecane (HBCD) stereoisomers in U.S. food from Dallas, Texas. Environ. Health Perspect. 120, 1260-1264. doi:http://dx.doi.org/10.1289/ehp.1204993

Schlummer, M., Brandl, F., Mäurer, A., van Eldik, R., 2005. Analysis of flame retardant additives in polymer fractions of waste of electric and electronic equipment (WEEE) by means of HPLC-UV/MS and GPC-HPLC-UV. J. Chromatogr. A 1064, 39-51. doi:10.1016/j.chroma.2004.12.016

Schlummer, M., Gruber, L., Mäurer, A., Wolz, G., van Eldik, R., 2007. Characterisation of polymer fractions from waste electrical and electronic equipment (WEEE) and implications for waste management. Chemosphere 67, 1866-1876. doi:10.1016/j.chemosphere.2006.05.077

Stapleton, H.M., Kelly, S.M., Pei, R., Letcher, R.J., Gunsch, C., 2008. Metabolism of Polybrominated Diphenyl Ethers (PBDEs) by Human Hepatocytes in Vitro. Environ. Health Perspect. 116, 727-733. doi:10.1289/ehp.

Švec, P., 1990. Styrene-based plastics and their modification. Ellis Horwood Ltd, Herts, UK.

UN, 2009. The Stockholm convention on persistant organic pollutants. Adoption of amendments to Annexes A, B and C. Reference: C.N.524.2009.TREATIES-4. Geneva, Switzerland.

UNEP, 2011. Hexabromocyclododecane. Draft risk management evaluation. Prepared by the ad hoc working group on Hexabromocyclododecane. Persistent Organix Pollutants Review Committee. Geneva, Switzerland.

Weber, R., Kuch, B., 2003. Relevance of BFRs and thermal conditions on the formation pathways of brominated and brominated-chlorinated dibenzodioxins and dibenzofurans. Environ. Int. 29, 699-710. doi:10.1016/S0160-4120(03)00118-1

Weil, E., Levchik, S., 2009. Flame Retardants for Plastics and Textiles - Practical Applications. pp. 
229-251. doi:10.3139/9783446430655.fm

WHO, 1997. Flame Retardants: A General Introduction, Environmental Health Criteria 192. World Health Organization (WHO). Geneva, Switzerland.

Wit, C.A. de, Kierkegaard, A., Ricklund, N., Sellström, U., 2011. Emerging Brominated Flame Retardants in the Environment, in: Eljarrat, E., Barceló, D. (Eds.), Brominated Flame Retardants, The Handbook of Environmental Chemistry. Springer Berlin Heidelberg, Berlin, Heidelberg, pp. 241-286. doi:10.1007/978-3-642-19269-2

Zion, 2015. Flame Retardant Chemicals (Aluminum Trihydrate (ATH), Antimony Oxides, Bromine, Chlorine, Organophosphorus and Others) Market for Building \&amp; Construction, Electronics, Automotive \&amp; Transportation, Wires \&amp; Cables, Textiles, and Other End-users: Global Industry Perspective, Comprehensive Analysis, and Forecast, 2014 - 2020. Zion Research. MRS - 38851 
Table 1. Deatiled sample description, concentration (bromophenols and HBCD in ng/g) and screening (PBDEs) for brominated flame retardants in household waste plastics.

\begin{tabular}{|c|c|c|c|c|c|c|c|c|c|c|c|c|c|c|c|c|}
\hline & & \multirow[b]{2}{*}{ Resin } & \multirow[b]{2}{*}{ Type $^{1}$} & \multicolumn{3}{|c|}{ Bromophenols } & \multicolumn{4}{|c|}{ Hexabromocyclododecane (HBCD) } & \multicolumn{6}{|c|}{ Polybrominated diphenyl ethers (PBDEs) } \\
\hline & & & & DBPs & 2,4,6-TBP & TBBPA & $\alpha-$ & $\beta-$ & $\gamma-$ & $\sum$ & 47 & 85 & 99 & 100 & 153 & 154 \\
\hline \multicolumn{2}{|c|}{$\mathrm{LOD}^{2}$} & - & - & 15 & 5 & 5 & 3 & 10 & 20 & - & - & - & - & - & - & - \\
\hline \multirow{20}{*}{ 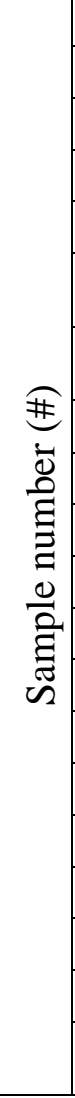 } & 1 & PET & $\mathrm{P}$ & $<\mathrm{LOD}$ & $<\mathrm{LOD}$ & $<\mathrm{LOD}$ & $<\mathrm{LOD}$ & $<\mathrm{LOD}$ & $<\mathrm{LOD}$ & - & - & - & - & - & - & - \\
\hline & 2 & HDPE & $\mathrm{P}$ & 250 & $<\mathrm{LOD}$ & $<\mathrm{LOD}$ & $<\mathrm{LOD}$ & $<\mathrm{LOD}$ & $<\mathrm{LOD}$ & - & - & - & - & - & - & - \\
\hline & 3 & PP & $\mathrm{P}$ & 240 & $<\mathrm{LOD}$ & $<\mathrm{LOD}$ & 20 & $<\mathrm{LOD}$ & $<\mathrm{LOD}$ & 20 & $\mathrm{x}$ & $\mathrm{x}$ & $\mathrm{x}$ & $\mathrm{x}$ & $\mathrm{x}$ & - \\
\hline & 4 & PS & $\mathrm{P}$ & $<\mathrm{LOD}$ & 680 & 4400 & 3600 & 970 & 550 & 5100 & - & - & - & - & - & - \\
\hline & 5 & ePS & $\mathrm{P}$ & $<\mathrm{LOD}$ & $<\mathrm{LOD}$ & $<\mathrm{LOD}$ & 52000 & 23000 & 250000 & 330000 & - & - & - & - & - & - \\
\hline & 6 & $\begin{array}{l}\text { ABS/ } \\
\text { other }\end{array}$ & $\mathrm{P}$ & $<\mathrm{LOD}$ & $<\mathrm{LOD}$ & $<$ LOD & $<\mathrm{LOD}$ & $<$ LOD & $<$ LOD & - & - & - & - & - & - & - \\
\hline & 7 & $\begin{array}{l}\text { Coated } \\
\text { foil }\end{array}$ & $\mathrm{P}$ & 20 & 10 & $<\mathrm{LOD}$ & $<\mathrm{LOD}$ & $<$ LOD & $<\mathrm{LOD}$ & - & - & - & - & - & - & - \\
\hline & 8 & Foil & $\mathrm{P}$ & 20 & $<\mathrm{LOD}$ & $<\mathrm{LOD}$ & 10 & $<\mathrm{LOD}$ & $<\mathrm{LOD}$ & 10 & - & - & - & - & - & - \\
\hline & 9 & NSP & $\mathrm{P}$ & $<\mathrm{LOD}$ & $<\mathrm{LOD}$ & 110 & 420 & 140 & 70 & 630 & - & - & - & - & - & - \\
\hline & 10 & PET & NP & $<$ LOD & 20 & 140 & 830 & 330 & 150 & 1300 & - & - & - & - & - & - \\
\hline & 11 & LDPE & NP & $<\mathrm{LOD}$ & $<\mathrm{LOD}$ & $<\mathrm{LOD}$ & $<\mathrm{LOD}$ & $<\mathrm{LOD}$ & $<\mathrm{LOD}$ & - & - & - & - & - & - & - \\
\hline & 12 & PP & NP & $<\mathrm{LOD}$ & 60 & 3000 & 10 & $<$ LOD & $<\mathrm{LOD}$ & 10 & - & - & - & - & - & - \\
\hline & 13 & NSP & NP & 40 & 230 & 2200 & 2000 & 690 & 440 & 3200 & - & - & - & - & - & - \\
\hline & 14 & PET & $\mathrm{P}$ & 50 & 10 & $<\mathrm{LOD}$ & $<\mathrm{LOD}$ & $<\mathrm{LOD}$ & $<\mathrm{LOD}$ & - & - & - & $\mathrm{x}$ & - & - & - \\
\hline & 15 & HDPE & $\mathrm{P}$ & 760 & $<\mathrm{LOD}$ & $<\mathrm{LOD}$ & $<\mathrm{LOD}$ & $<$ LOD & $<\mathrm{LOD}$ & - & - & - & - & - & - & - \\
\hline & 16 & PP & $\mathrm{P}$ & $<\mathrm{LOD}$ & $<\mathrm{LOD}$ & $<\mathrm{LOD}$ & $<\mathrm{LOD}$ & $<\mathrm{LOD}$ & $<\mathrm{LOD}$ & - & - & - & - & - & - & - \\
\hline & 17 & PS & $\mathrm{P}$ & 20 & 30 & 1200 & 330 & 110 & 70 & 500 & - & - & - & - & - & - \\
\hline & 18 & Foil & $\mathrm{P}$ & 30 & $<\mathrm{LOD}$ & 20 & 30 & $<\mathrm{LOD}$ & 160 & 190 & - & - & - & - & - & - \\
\hline & 19 & NSP & $\mathrm{P}$ & 70 & 100 & 1200 & 210 & 60 & $<\mathrm{LOD}$ & 270 & - & - & - & - & - & - \\
\hline & 20 & $\begin{array}{l}\text { ABS/ } \\
\text { other }\end{array}$ & $\mathrm{NP}$ & $<\mathrm{LOD}$ & $<\mathrm{LOD}$ & $<\mathrm{LOD}$ & $<\mathrm{LOD}$ & $<$ LOD & $<\mathrm{LOD}$ & - & - & - & - & - & - & - \\
\hline \multicolumn{2}{|c|}{$\mathrm{FOD}^{3}$} & - & - & $50 \%$ & $40 \%$ & $40 \%$ & $\mathbf{5 0 \%}$ & $35 \%$ & $35 \%$ & - & $5 \%$ & $5 \%$ & $10 \%$ & $5 \%$ & $5 \%$ & $0 \%$ \\
\hline
\end{tabular}

${ }^{1}$ P: Packaging, NP: Non packaging; ${ }^{2}$ LOD: Limit of detection; ${ }^{3}$ FOD: Frequency of detection. 
Table 2. Deatiled sample description, concentration (bromophenols and HBCD in ng/g) and screening (PBDEs) for brominated flame retardants in processed plastics obtained from virgin production and recycling.

\begin{tabular}{|c|c|c|c|c|c|c|c|c|c|c|c|c|c|c|c|c|c|}
\hline \multirow{3}{*}{\multicolumn{2}{|c|}{$\mathrm{LOD}^{3}$}} & \multirow{4}{*}{$\begin{array}{c}\text { Resin } \\
- \\
\text { PET }\end{array}$} & \multirow{4}{*}{$\begin{array}{c}\text { Type }^{1} \\
- \\
\text { V }\end{array}$} & \multirow{4}{*}{$\begin{array}{c}\text { Source }^{2} \\
- \\
-\end{array}$} & \multicolumn{3}{|c|}{ Bromophenols } & \multicolumn{4}{|c|}{ Hexabromocyclododecane (HBCD) } & \multicolumn{6}{|c|}{ Polybrominated diphenyl ethers (PBDEs) } \\
\hline & & & & & \multirow{3}{*}{$\begin{array}{c}\text { DBPs } \\
\mathbf{1 5} \\
<\text { LOD }\end{array}$} & \multirow{3}{*}{$\begin{array}{c}\mathbf{2 , 4 , 6 - T B P} \\
\mathbf{5} \\
<\text { LOD }\end{array}$} & \multirow{3}{*}{$\begin{array}{c}\text { TBBPA } \\
\mathbf{5} \\
<\text { LOD }\end{array}$} & \multirow{3}{*}{$\begin{array}{c}\boldsymbol{\alpha}- \\
\mathbf{3} \\
\text { LOD }\end{array}$} & \multirow{3}{*}{$\begin{array}{c}\boldsymbol{\beta}- \\
\mathbf{1 0} \\
<\text { LOD }\end{array}$} & \multirow{3}{*}{$\begin{array}{c}\boldsymbol{\gamma}- \\
\mathbf{2 0} \\
<\text { LOD }\end{array}$} & \multirow{3}{*}{$\begin{array}{l}\sum \\
- \\
-\end{array}$} & \multirow{2}{*}{$\begin{array}{c}47 \\
- \\
\end{array}$} & \multirow{2}{*}{$\begin{array}{c}85 \\
- \\
\end{array}$} & \multirow{3}{*}{$\begin{array}{c}99 \\
- \\
-\end{array}$} & \multirow{3}{*}{$\begin{array}{c}100 \\
- \\
-\end{array}$} & \multirow{3}{*}{$\begin{array}{c}153 \\
- \\
-\end{array}$} & \multirow{3}{*}{$\begin{array}{c}154 \\
- \\
-\end{array}$} \\
\hline & & & & & & & & & & & & & & & & & \\
\hline \multirow{28}{*}{ 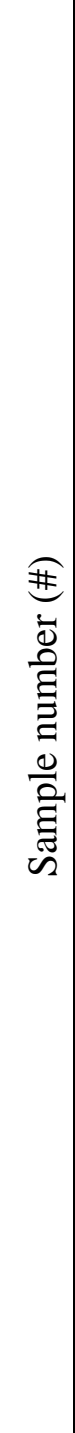 } & 1 & & & & & & & & & & & - & - & & & & \\
\hline & 2 & HDPE & $\mathrm{V}$ & - & $<\mathrm{LOD}$ & $<\mathrm{LOD}$ & $<\mathrm{LOD}$ & $<\mathrm{LOD}$ & $<\mathrm{LOD}$ & $<\mathrm{LOD}$ & - & $\mathrm{x}$ & - & $\mathrm{x}$ & - & - & - \\
\hline & 3 & LDPE & $\mathrm{V}$ & - & $<\mathrm{LOD}$ & $<\mathrm{LOD}$ & $<\mathrm{LOD}$ & $<\mathrm{LOD}$ & $<\mathrm{LOD}$ & $<\mathrm{LOD}$ & - & - & - & - & - & - & - \\
\hline & 4 & LDPE(L) & $\mathrm{V}$ & - & $<\mathrm{LOD}$ & $<\mathrm{LOD}$ & $<\mathrm{LOD}$ & $<\mathrm{LOD}$ & $<\mathrm{LOD}$ & $<\mathrm{LOD}$ & - & - & - & $\mathrm{x}$ & - & - & - \\
\hline & 5 & $\mathrm{PP}$ & $\mathrm{V}$ & - & $<\mathrm{LOD}$ & $<\mathrm{LOD}$ & $<\mathrm{LOD}$ & $<\mathrm{LOD}$ & $<\mathrm{LOD}$ & $<\mathrm{LOD}$ & - & - & - & - & - & - & - \\
\hline & 6 & PP & $\mathrm{V}$ & - & $<\mathrm{LOD}$ & $<\mathrm{LOD}$ & $<\mathrm{LOD}$ & $<\mathrm{LOD}$ & $<$ LOD & $<$ LOD & - & $\mathrm{x}$ & - & $\mathrm{x}$ & - & $\mathrm{x}$ & - \\
\hline & 7 & PS & $\mathrm{V}$ & - & 20 & $<\mathrm{LOD}$ & $<\mathrm{LOD}$ & 10 & $<\mathrm{LOD}$ & $<\mathrm{LOD}$ & 10 & $\mathrm{x}$ & - & $\mathrm{x}$ & $\mathrm{x}$ & $\mathrm{x}$ & $\mathrm{x}$ \\
\hline & 8 & PS & $\mathrm{V}$ & - & 30 & $<\mathrm{LOD}$ & $<\mathrm{LOD}$ & 10 & $<\mathrm{LOD}$ & $<\mathrm{LOD}$ & 10 & - & - & - & - & - & - \\
\hline & 9 & PET & $\mathrm{R}$ & IW & $<$ LOD & $<\mathrm{LOD}$ & $<\mathrm{LOD}$ & $<$ LOD & $<$ LOD & $<$ LOD & - & - & - & - & - & - & - \\
\hline & 10 & PET & $\mathrm{R}$ & IW & $<\mathrm{LOD}$ & $<\mathrm{LOD}$ & 120 & $<\mathrm{LOD}$ & $<\mathrm{LOD}$ & $<$ LOD & - & - & - & - & - & - & - \\
\hline & 11 & PET(G) & $\mathrm{R}$ & IW & $<\mathrm{LOD}$ & $<\mathrm{LOD}$ & $<\mathrm{LOD}$ & $<\mathrm{LOD}$ & $<\mathrm{LOD}$ & $<\mathrm{LOD}$ & - & $\mathrm{x}$ & - & $\mathrm{x}$ & - & - & - \\
\hline & 12 & PET & $\mathrm{R}$ & HHW & $<\mathrm{LOD}$ & $<\mathrm{LOD}$ & $<\mathrm{LOD}$ & $<\mathrm{LOD}$ & $<\mathrm{LOD}$ & $<\mathrm{LOD}$ & - & $\mathrm{x}$ & - & $\mathrm{x}$ & - & - & - \\
\hline & 13 & HDPE & $\mathrm{R}$ & HHW & $<\mathrm{LOD}$ & 20 & 120 & $<$ LOD & $<$ LOD & $<\mathrm{LOD}$ & - & - & - & - & - & - & - \\
\hline & 14 & HDPE & $\mathrm{R}$ & IW & $<\mathrm{LOD}$ & $<\mathrm{LOD}$ & $<\mathrm{LOD}$ & $<\mathrm{LOD}$ & $<$ LOD & $<\mathrm{LOD}$ & - & $\mathrm{x}$ & - & $\mathrm{x}$ & - & - & - \\
\hline & 15 & HDPE & $\mathrm{R}$ & IW & $<\mathrm{LOD}$ & 10 & 100 & $<$ LOD & $<$ LOD & $<$ LOD & - & - & - & - & - & - & - \\
\hline & 16 & HDPE & $\mathrm{R}$ & HHW & $<\mathrm{LOD}$ & $<\mathrm{LOD}$ & $<\mathrm{LOD}$ & $<\mathrm{LOD}$ & $<\mathrm{LOD}$ & $<$ LOD & - & - & - & - & - & - & - \\
\hline & 17 & HDPE & $\mathrm{R}$ & HHW & $<\mathrm{LOD}$ & $<\mathrm{LOD}$ & 20 & 80 & $<\mathrm{LOD}$ & $<\mathrm{LOD}$ & 80 & $x$ & - & $\mathrm{x}$ & - & - & - \\
\hline & 18 & HDPE & $\mathrm{R}$ & HHW & $<\mathrm{LOD}$ & $<\mathrm{LOD}$ & $<\mathrm{LOD}$ & $<\mathrm{LOD}$ & $<$ LOD & $<\mathrm{LOD}$ & - & - & - & - & - & - & - \\
\hline & 19 & LDPE & $\mathrm{R}$ & IW & $<$ LOD & $<\mathrm{LOD}$ & $<\mathrm{LOD}$ & $<\mathrm{LOD}$ & $<$ LOD & $<\mathrm{LOD}$ & - & - & - & - & - & - & - \\
\hline & 20 & LDPE & $\mathrm{R}$ & HHW & $<$ LOD & $<\mathrm{LOD}$ & 10 & $<$ LOD & $<$ LOD & $<$ LOD & - & $\mathrm{x}$ & - & $\mathrm{x}$ & $\mathrm{x}$ & - & - \\
\hline & 21 & LDPE & $\mathrm{R}$ & IW & $<\mathrm{LOD}$ & $<\mathrm{LOD}$ & $<\mathrm{LOD}$ & $<\mathrm{LOD}$ & $<\mathrm{LOD}$ & $<\mathrm{LOD}$ & - & $\mathrm{x}$ & - & $\mathrm{x}$ & - & - & - \\
\hline & 22 & LDPE(L) & $\mathrm{R}$ & IW & $<\mathrm{LOD}$ & $<\mathrm{LOD}$ & $<\mathrm{LOD}$ & $<\mathrm{LOD}$ & $<\mathrm{LOD}$ & $<\mathrm{LOD}$ & - & - & - & $\mathrm{x}$ & - & - & - \\
\hline & 23 & PP & $\mathrm{R}$ & HHW & $<\mathrm{LOD}$ & $<\mathrm{LOD}$ & 110 & 40 & $<\mathrm{LOD}$ & $<\mathrm{LOD}$ & 40 & - & - & - & - & - & - \\
\hline & 24 & PP & $\mathrm{R}$ & IW & $<\mathrm{LOD}$ & $<\mathrm{LOD}$ & 6400 & $<\mathrm{LOD}$ & $<\mathrm{LOD}$ & $<\mathrm{LOD}$ & - & - & - & - & - & - & - \\
\hline & 25 & PP & $\mathrm{R}$ & HHW & $<\mathrm{LOD}$ & 20 & 50 & 30 & $<$ LOD & $<\mathrm{LOD}$ & 30 & - & - & $\mathrm{x}$ & $\mathrm{x}$ & - & - \\
\hline & 26 & PP & $\mathrm{R}$ & IW & $<$ LOD & $<\mathrm{LOD}$ & 14 & $<\mathrm{LOD}$ & $<$ LOD & $<$ LOD & - & - & - & - & - & - & - \\
\hline & 27 & $\mathrm{PP}$ & $\mathrm{R}$ & IW & 25 & $<\mathrm{LOD}$ & $<\mathrm{LOD}$ & $<$ LOD & $<\mathrm{LOD}$ & $<$ LOD & - & - & - & - & - & - & - \\
\hline & 28 & PP & $\mathrm{R}$ & HHW & $<\mathrm{LOD}$ & 10 & 60 & 60 & $<\mathrm{LOD}$ & $<\mathrm{LOD}$ & 60 & - & - & - & - & - & - \\
\hline
\end{tabular}




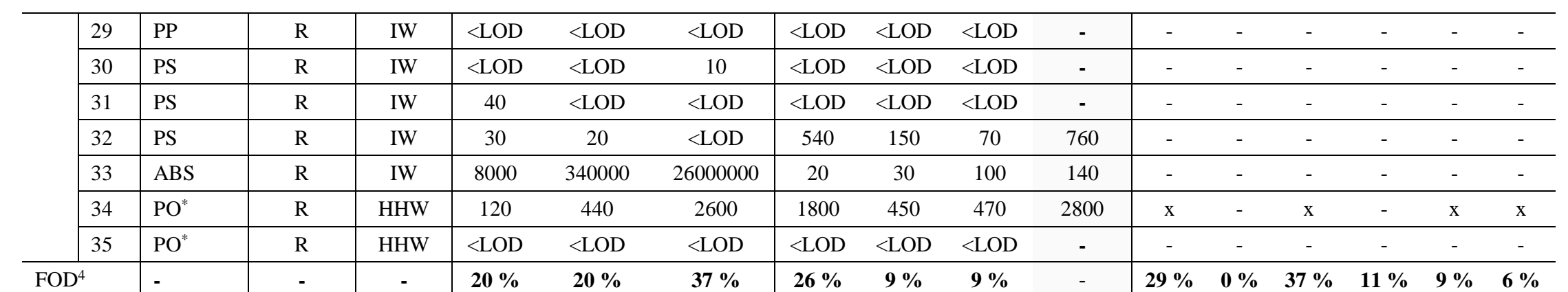

${ }^{1}$ R: Recycled, V: Virgin; ${ }^{2}$ IW: Industrial Waste plastics; HHW: Household Waste plastics; ${ }^{3}$ LOD: Limit of detection; ${ }^{4}$ FOD: Frequency of detection; ${ }^{*}$ Includes a non-defined mixture of common polymers produced from single olefin (i.e. polyethylene and polypropylene) 